\title{
The role of the clinical examination in manasement of temporo-mandibular and cervical disorders
}

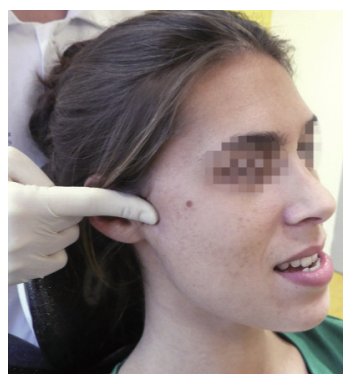

\section{Audrey CHANLON, Hatem BEDOUI, Bernard FLEITER}

\begin{abstract}
The diagnosis of functional temporo-mandibular and cervical problems depends to a great extent on subjective information provided by patients. As a result, it is difficult to arrive at a substantiated assessment of the prevalence of these disorders. Based on the data reported from large-scale epidemiological studies, it appears that nearly $50 \%$ of the populations of developed countries have symptoms of musculo-skeletal problems. The over-abundance of diagnostic tests suggested for assessing this problem adds confusion to this murky area. The purpose of this article is to precisely evaluate the pertinence of the various tests used to establish a clinical diagnosis.
\end{abstract}

\section{KEY WORDS}

$$
\begin{aligned}
& \text { Pain } \\
& \text { Malfunction } \\
& \text { Dysfunction } \\
& \text { Diagnostic test } \\
& \text { Clinical diagnosis. }
\end{aligned}
$$

\section{1 - INTRODUCTION}

The term Temporo-Mandibular - Disorders, TMD, encompasses an ensemble of pain and muscular or articular malfunctions.
Diagnosing them is especially difficult because of the multiplicity of suspected causative factors $^{28}$.

Address for correspondence:

A. CHANLON

Faculté d'Odontologie

Université de Paris Descartes

1 , rue Maurice-Arnoux,

92120 Montrouge

chanlon.audrey@gmail.com 
Musculo-skeletal disorders appear to occur quite frequently but studies vary in assessing the extent to which cranio-cervical problems contribute to $\mathrm{TMD}^{2}$ and what their clinical implications may be.

In 1992, Dworkin and LeResche and their co-workers presented their Research Diagnostic Criteria for TMD, which uses a dual-axis approach to diagnose and classify physical findings, psychological status, and psychosocial functioning as a guide for conducting pain research.

In 2009, modifications were proposed for inclusion of patients so that these criteria would be more easily employed clinically. But the validity of these criteria is still being disputed ${ }^{4}$.

In adolescents, the group most frequently treated orthodontically, there is a great variation of the signs and symptoms of TMD. Such indications increase with young adults and then stabilize, and, probably, decrease.

In view of this, Hasaanain ${ }^{13}$ has suggested that orthodontic treatment can be considered to be a provocation for the onset of transient temporomandibular disorders. But the majority of studies show that orthodontic treatment has no deleterious effect on the masticatory apparatus.

Nevertheless, it would be prudent for orthodontists to make a pre-treatment assessment of muscles and articulations, focused, if indicated, on a history of pain or malfunctions and a clinical examination featuring a number of tests. These require the cooperation of patients who must inform the examiner after each maneuver how the sensations they experienced should be scored on a visual analog scale or on a verbal scale ${ }^{18,29}$.

In this article, we shall report on the tests now in common use and appraise their validity and reliability. Functional examinations are designed to allow the practitioner to grade the extent patients have lost control of a specific action and to uncover the pain associated with that loss.

\section{2 - SOME USEFUL TERMS}

- Validity - this is a measurement of the extent to which a diagnostic test can rate the presence or absence of a disorder in a group of individuals. We shall evaluate a test by comparing it to a standard reference test, the gold standard, in terms of its sensitivity and its specificity.

- Sensitivity - is the capacity of a test to detect the persons suffering from a disorder in the group testing positive. It is the proportion of sick subjects testing positive or the

proportion of actual positives that are correctly identified as such.

- Specificity is the capacity of a test to detect the healthy subjects in the negative responses to a test, the proportion of negatives that are correctly identified as not having the condition.

- Reliability or consistency measures the extent to which tests can be replicated or the confidence that can be accorded to them. 
- Kappa measures the extent to which tests can be replicated compared to what pure chance would have given. Also called inter-rater agreement, kappa reliability increases with the extent it differs from pure chance $(K$ reliable $>0.80$ ).

- ICC is the intra-class correlation coefficient, the proportion of variance of an observation in the same subject due to between-

\section{3 - DIAGNOSTIC TESTS}

\section{- Diagnostic tests}

These are used to make a differential diagnosis between pain coming from teeth, pain coming from temporo-mandibular disorders, and ophthalmological and other ENT pain.

Using the results of these instruments dentists can decide whether or not the patient is suffering from a disorder in a region that falls within their sphere of competence.

\section{- Clinical tests}

These are accomplished with a variety of techniques:

- palpation of muscles or joints,

- assessing mandibular movements,

- assessing movement of the head and neck,

- active and passive tests,

- dynamic and static tests,

- assessment of articular noises,

- assessment of cranio-cervical posture.

The clinical interview is an indispensable tool that should be completed before the clinical exam begins. It supplies the examiner with important data on the characteristics of the pain subject variability in the true scores. This corresponds to the biological proportion of the total variability. The greater the proportion is, the more the measurement is reliable (ICC reliable $>0.80)$.

"The level of reliability associated with a diagnostic instrument can be a limiting factor for its diagnostic validity $27 . "$ and helps the examiner to choose the appropriate tests that will eventually be employed.

Dentists begin their clinical examination by inspecting the patient's external facial features, temporo-mandibular joint, neck, and head. In this inspection dentists look for asymmetry that might be caused by a growth, a swelling, a traumatic incident, edema, or partial paralysis.

\section{3 - 1 - Palpation of the muscles of mastication and the TMJ}

It is difficult to compare the results of studies on muscular and joint palpation because the methods, the sites, and the pressures exerted vary between the teams that carried out exams $^{8-11}$.

Examiners place themselves on the midline behind the patient in dorsal decubitus and carry out a simultaneously bilateral examination of the muscles and joints, palpating with the 

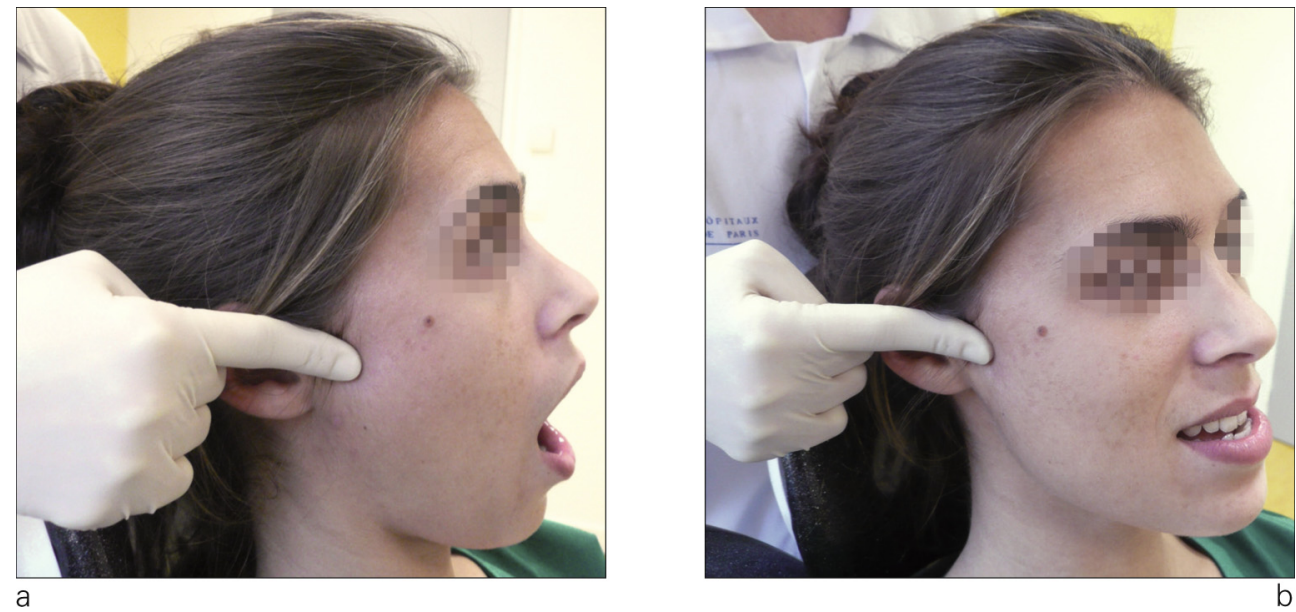

Figures 1 and $b$

Examiners should palpate of the lateral pole of the TMJ during different mandibular movements. Here the patient's mouth is partially open (a) and in propulsion (b). The examiner is located behind the semi-recumbent or recumbent patient. The palpations are bilateral, symmetrical, and simultaneous.

\begin{tabular}{|c|c|c|c|c|}
\hline & \multicolumn{2}{|c|}{ ICC } & SENSITIVITY & SPECIFICITY \\
\hline & List 2006 & LOBBEZOO 2005 & \multicolumn{2}{|c|}{ GOMES 2008} \\
\hline Right temporal & & & 67.5 & 87.5 \\
\hline Left temporal & & & 62.5 & 90 \\
\hline Posterior temporal & 0.73 & 0.1 & & \\
\hline Middle temporal & & 0.44 & & \\
\hline Anterior temporal & & 0.56 & & \\
\hline Right masseter & & & 75 & 90 \\
\hline Left masseter & & & 77.5 & 90 \\
\hline Superior masseter & & 0.75 & & \\
\hline masseter & & .63 & & \\
\hline Inferior masseter & & 0.58 & & \\
\hline Right TMJ & & & 56.4 & 95 \\
\hline Left TMJ & & & 75 & 95 \\
\hline Lateral pole of the TMJ & 0.69 & 0.38 & & \\
\hline Posterior pole of the TMJ & 0.83 & & & \\
\hline
\end{tabular}

Table 1

Palpation of the masseter and the posterior pole of the TMJ seems to be the most reliable.

index and major fingers or the index finger alone. Palpation pressure is maintained for 2 to 4 seconds with a force of $10 \mathrm{~N}$ for muscles and $5 \mathrm{~N}$ for the TMJ. After each test palpation, the examiner asks the patient to grade the sensitivity or pain, for eventual scoring it on a visual analog scale. 


\section{- Palpation of the muscles of mastication}

The two principle muscles to be palpated are the masseter and the temporal, but the medial ptyergoid can also be palpated, internally, at the mandibular angle.

\section{- Palpation of the lateral pole of the TMJ}

The examiner places her index finger $1 \mathrm{~cm}$ anterior to the tragus of the ear and asks the patient to open his mouth slowly until a translation of the Lateral pole of the condyle can be felt. The examiner exerts about $5 \mathrm{~N}$ pressure on the palpated surface while holding the patient's head steady with the other hand.

\section{- Palpation of the posterior pole}

The examiner palpates this site by placing his little finger within the opening of the external auditory meatus and asks the patient to open his mouth in order to be sure the articular movement can be clearly felt. Then a firm pressure is maintained as the patient closes his mouth.

In palpating the muscles of mastication the examiner can evaluate the extent that they contract.

Noxious habits or dysfunctions like tooth grinding, bruxism, atypical swallowing, and excessive gum chewing can lead to muscular contraction that is often painful. Examiners can reproduce such muscular pain by digital pressure that can be objectified in a calibration that is quite important because it will, to a great extent, determine the result of the test ${ }^{11}$.

The practitioner palpates the median portion of the masseter after having discerned the muscle's volume and the simultaneous nature of isometric contraction. Palpation of the median part of the mandibular insertion gives the examiner access to the superficial and intermediate masseter. Palpation of the upper insertion more posteriorly provides access to the intermediate and deep masseter bundles because of the "playing card" fashion in which this muscle is organized.

For palpation of the temporal muscles examiners place themselves in front of the patient and use one or three fingers simultaneously on right and left sides. The orbital, bulkiest part of the muscle is readily detectable and is an area that is often painful.

During palpation of the TMJ, examiners discern the external poles of the right and left condyles while having the patient make small opening and closing movements of the mandible. From this vantage point the examiner is looking for the articular interline while the patient holds his mouth slightly open. The interline is limited below and to the rear by the mandibular condyle and forward and above by the zygomatic eminences of the temporal bone.

\section{3 - 2 - Cervical palpation}

The musculo-articular cranio-cervical examination is far from standardized and varies in accordance with the training examiners have received. Physicians, rheumatologists, osteopaths, chiropractors, physical therapists, and dentists do not employ the same maneuvers and look quite different patterns of evidence. Moreover, the replication of these maneuvers is 
poorly documented in the literature and studies on this theme are rare and often quite segmented ${ }^{19}$.

\section{3-2 - 1 - Muscular palpation}

The examiner palpates muscles with the patient in dorsal decubitus bilaterally looking for sore spots with the index and middle fingers with a $10 \mathrm{~N}$ pressure.

Adrade ${ }^{1}$ asserted that cervical muscles show a greater sensitivity to palpation in patients with TMD than do groups of asymptomatic individuals.

Many studies have attempted to test the validity of cervical muscular palpation as a diagnostic sign of TMD. But reproducibility between operators is no better than average except for the trapezius muscle.

- Maigne $2009^{19}$

average $\mathrm{Kappa}=0.44$.

- Visscher $2000^{29}$

- kappa $=0.46$ to 0.73 ;

- Pearson's correlation coefficient $=0.61$ to 0.92 ;

- sensitivity $=61.7$;

- specificity $=57.9^{\prime}$

Ylinen $2007^{33}$ :

$\mathrm{ICC}=0.78-0.93$ for the trapezius.

\section{- Posterior muscles}

The principle posterior muscles to be palpated are:

- semispinal: in in its superior, medial, and inferior cervical portions

- scapular elevator muscle: at its insertion on the supero-medial angle of the scapula ${ }^{11}$ and at the center of the scapula ${ }^{29}$;

- splenius of the neck: at its insertion on the lateral surface vertebra T4;
- trapezius: at the center of different quadrants ${ }^{29}$ and in its fleshy portion at the level of the cervico-scapular angle $^{19}$. The examiner palpates a large part of the extended muscle. The clenched muscle is palpated on the upper-lateral border of the Splenius of the head, about $2 \mathrm{~cm}$. its insertion between the lateral border of the trapezius muscle and the posterior border of the sternocleido-mastoid muscle.

\section{- Lateral muscles}

Orthodontists can palpate the sterno-cleido-mastoid muscle in three sites along its body. By pinching the upper portion, not the underlying bone, they can outline that body, getting an even clearer sense of it by asking patients to turn their heads from right to left during the palpation. This is one of the few muscles that can be palpated unilaterally.

\section{- Anterior muscles}

The inferior and superior hyoid muscles, the mylohyoid, the hypoglossal, the geniohyoid, and the digastric group constitute the anterior muscles.

It is not known what an anomaly of the mobility or sensibility of the hyoid muscles signifies ${ }^{4}$.

The sensitivity to palpation of these muscles must be distinguished from referred pain associated with trigger points in the cadre of myofacial pain, which can be found in tense muscle bands sensitive to palpation that were the trigger points described by Janet Travell and Simon.

The many trigger points in the cervical region include: 
- the trapezius muscle that can refer pain to the head, the neck, and the orbital and peri-orbital regions;

- the sterno-cleido-mastoid muscle that can refer pain to the frontotemporal region, the occiput, the vertex, the forehead, and the orbit;

- the splenius muscle of the neck that can refer pain to the vertex area of the head on the same side, the back of the head, and the occiput;

- the occipital-cervical muscles that can refer pain to the occiput, the eye, and the forehead.

Referred pain can be the actual origin of headaches that seem to have cervical basis. With headaches of this type, a stimulus of the trigger point will exacerbate the pain. But the reverse is also true, inactivation of the trigger points, perhaps with local anesthetic, will eliminate the pain.

Sub-occipital muscle trigger points can provoke referred occipital neuralgia.

\section{3 - 2 - 2 - Examination of sectors}

This type of examination is a basic tool of physical medecine ${ }^{19}$. Examiners stand by the heads of patients who are lying on their backs, flexing neck muscles looking for segmented sensibility in para-vertebral areas, using upper cervical C 2 and C 7, middle cervical C 1-3, and lower C 5-7 spines as landmarks.

However, we do not know whether or not positive segmental findings actually reflect a problem of the vertebrae, zygapophyseal joint; of a disc, of the periosteum or of the muscles that cover them (Kappa average $=0.53$.

By palpating the cervical zygapophyseal joints examiners can differentiate

\begin{tabular}{|l|c|c|}
\hline \multicolumn{1}{|c|}{ MANDIBULAR } & \multicolumn{2}{|c|}{ ICC } \\
\hline \multicolumn{1}{|c|}{ MOVMENTS } & List & LOBBEZOO \\
2005
\end{tabular}

Table /I

The most reliable tests are opening and propulsive. The difficulty patients have in moving their jaws laterally may explain the poor reliability of testing for this excursion.

between subjects with cervical pain and healthy subjects with $82 \%$ sensitivity and a $79 \%$ specificity $^{19-25}$.

The correlation between high pain and limited rotation on cervical examination is said to be poor ${ }^{19}$.

\section{3 - 3 - Mandibular movements}

Examiners ask patients if they feel pain during a single or multiple movements of the mandible such as opening and closing, left and right lateral excursions, and propulsive and return movements. Using a ruler, the examiner can record the extent of each movement in millimeters using the mesio-occlusal maxillary and mandibular incisor angle as a reference point.

To do this they must take overbite, overjet, and a possible gap between incisal edges into account when quantifying lateral movements.

Examiners should ask patients to repeat these movements at least three times to be sure they are recording reproducible results. 

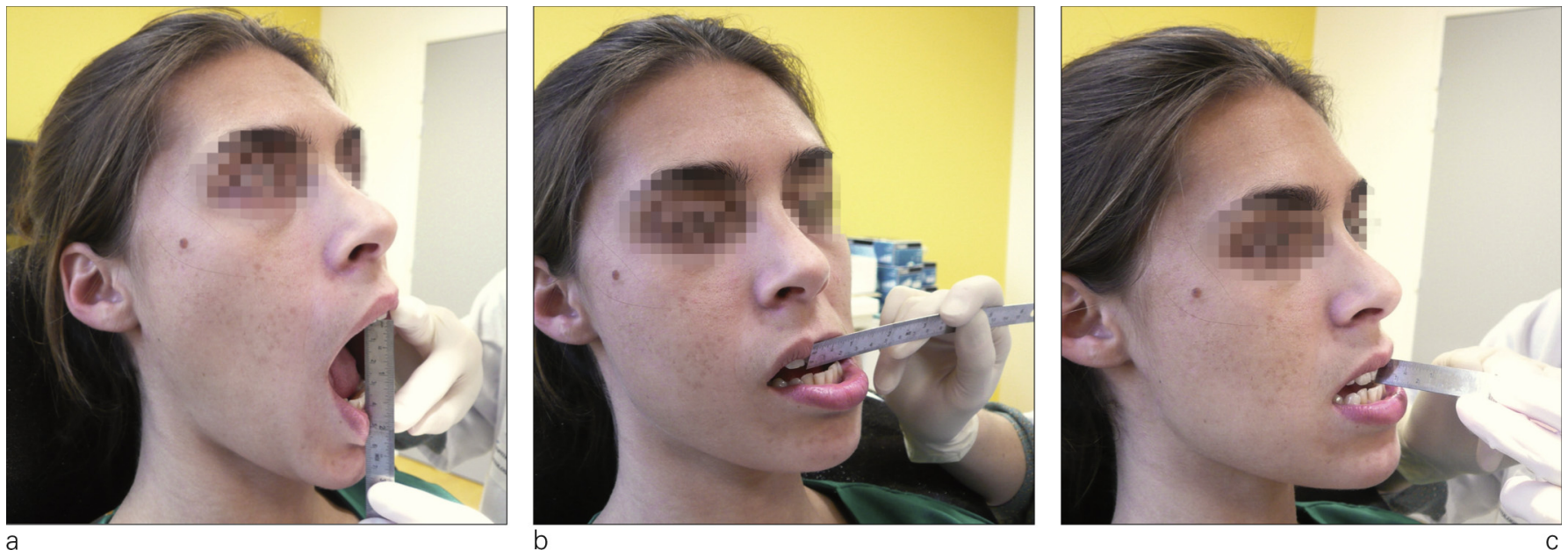

Figures 2 a to $c$

Measuring active mandibular movements (without assistance.) Here maximum opening, right lateral, and propulsive movements are depicted.
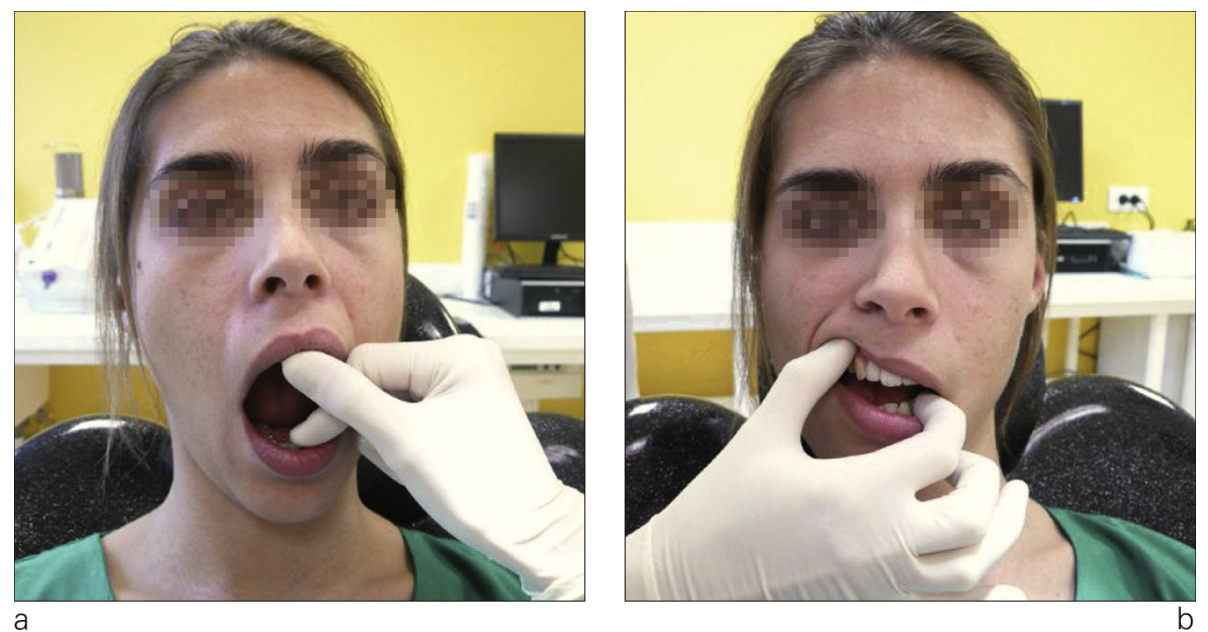

Figures $3 a$ and $b$

Example of passive (with assistance) movement: maximum opening and right lateral.

\section{3-3-1 - Active and passive movements}

\section{- Active opening without pain}

The examiner asks the patient to open as widely as possible and to stop when the first sign of pain is felt.

\section{- Maximal active opening}

The examiner asks the patient asks the patient to open as widely as possible disregarding pain. 

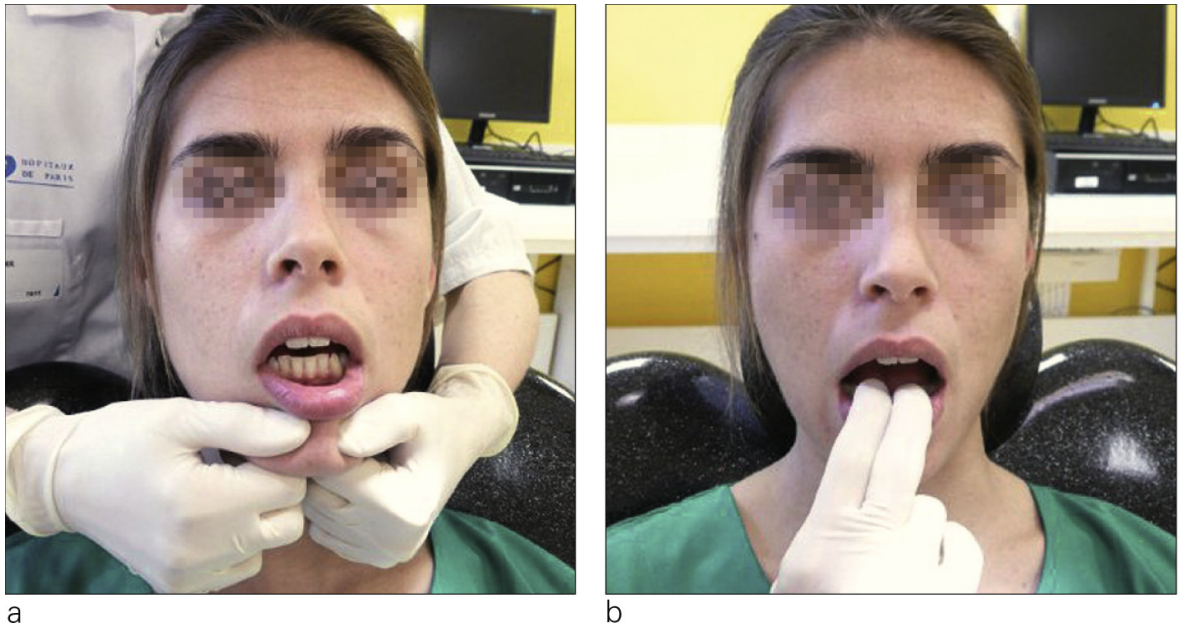

Figures 4 a to $c$

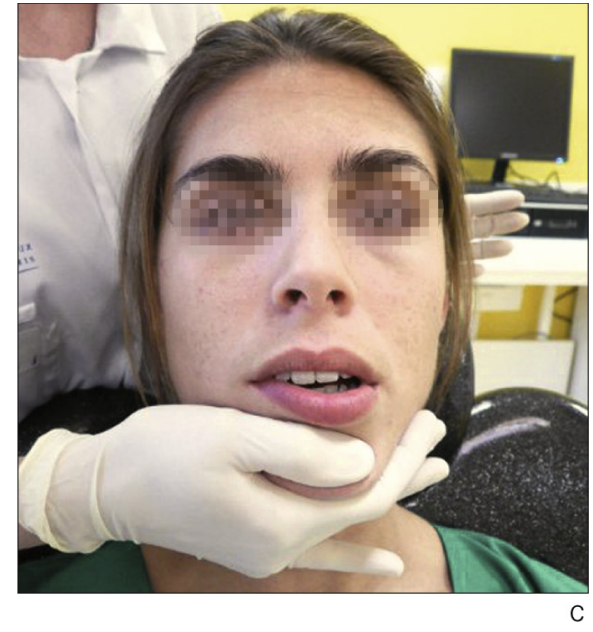

Illustrations of patient jaw against resistance from left to right, static closing, dynamic closing, and static opening.

\section{- Passive (assisted) maximum opening}

The examiner asks the patient to open as far as possible and then increases this opening by placing thumb against the maxillary incisors and index finger against the lower incisors and exerting moderate pressure to attempt to reach the maximum mandibular opening.

\section{- Right and left lateral move- ments}

The patient is asked to execute the widest possible lateral excursive movements, which is often difficult for them to do. The examiner then guides the patient in lateral movements

\section{- Propulsion}

The examiner asks patients to move their chins as far forward as possible, always asking if pain is felt and on which side.

By measuring the movements, the examiner can assess the extent of limitation.
Usually, the average of the amplitude of lateral and propulsive movements should be $1 / 4$ of the amplitude of maximal opening.

If the amplitude of the maximal active opening is many millimeters less than the amplitude of the maximal passive opening, a muscular problem is causing the limitation.

But if the examiner notes little or no difference between active and passive opening, an articular problem is causing the limitation.

This localization of pain as provoked by muscular or articular sources, also helps to orient the examiner's diagnosis of the problem's origin as being muscular or articular.

\section{3 - 3 - 2 - Dynamic and static tests}

By using dynamic and static tests, orthodontists can distinguish between health patients and those suffering from temporo-mandibular disorders in muscular and articular palpation ${ }^{29}$. 
In dynamic testing, patients are asked to execute various mandibular movements while the examiner opposes these excursions with gentle pressure. The patient is asked to maintain the movement despite the resistance.

During static tests, the examiner asks patients to keep their mandibles immobile while exerting light gradually increasing pressure until either the patient or examiner reaches a maximal effort, which is maintained for 3 seconds.

The patients are asked if they felt pain during the procedure.

These tests have a $65 \%$ sensitivity and an 84 to $91 \%$ specificity level ${ }^{30}$.

The appearance of pain during these static TMJ tests indicates likelihood that the etiology of the TMD is muscular.

The dynamic tests do not help the examiner to determine whether the etiology is muscular or articular but do objectify the sites of pain.

\section{3 - 4 - Articular sounds}

Frequently cited by patients as the chief complaint that triggered their consultation visit, articular sounds in the form of clicking or crackling are experienced by 15 to $40 \%$ of the general population. Disc displacement is frequently the cause of TMJ clicking and is a symptom of reducible anterior disc displacement ${ }^{15}$.

In order to intensify and clarify articular sounds, examiners may choose to use a stethoscope.

\section{- Clicking}

An abrupt noise of short duration, clicking has a distinct beginning and ending as well distinct sound aptly described as a "clack."

\section{- Crackling}

This type of sound continues for a long period as the jaw is opened or closed and has no well delimited "click." It resembles a grinding or scratching noise. Clicking that does not repeat itself two or three times is not considered to be reproducible and its origin is difficult to establish.

IN 2008 Manfredini ${ }^{21}$ questioned the widely held belief that clicking was necessarily associated with luxation or anterior disc displacement. He found that MRI films of patients with clicking did not show this abnormal disc position in $33.9 \%$ of cases. On the other hand, MRI films showed disc displacement in $54.4 \%$ of the population who demonstrated no clinical signs of clicking.

Huddleston ${ }^{14}$ reminds us that anterior disc displacement with reduction is described as an anterior change in the position of the disc between the condyle and the articular eminence at maximal intercuspation that is reduced when patients open their jaws.

In propulsion or retropulsion no luxation of the disc is possible because the condyle does not return into the depth of the mandibular fossa, which would seem to make propulsion a good test for distinguishing between sub-groups.

Clicking is a sinusoidal vibration sound that may or may not be accompanied by harmonics of its frequency, which quite briefly is heard below the patient's ear. Its timber and intensity are variable. 
Crackling consists of different nonharmonic superimposed frequencies that combine to make a perceptibly continuous grating sound that resembles noises made by heels walking on gravel or the crinkling of paper or silk.

\section{3 - 5 - Cervical mobility}

When head and neck mobility are measurably limited this is a sign of pathology. There may be a relationship between their mobility in flexing, extension, and rotation and the sensitivity of the muscles of mastication ${ }^{5}$.

The examiner should first conduct active and then passive tests, listening for articular noises emanating from the neck of the patient should be sitting upright with spine supported by chair.

An examiner may use a variety of tools for measuring cervical mobility, including inclinometer, goniometer, and tape measure, but a simple visual evaluation during the course of the exam, without tools, is not reliable ${ }^{25}$.

The patient should be seated upright, with the thoracic and lumbar portions of the vertebral column well supported.

\section{3-5-1-Movement of rotation}

The examiner asks patients to rotate their necks from right to left, blocking the $\mathrm{T} 1$ spine with a thumb to be sure the movement elicited is exclusively cervical:

- normal or moderately limited according to Maigne ${ }^{19}>70^{\circ}$ according to Rozenberg $85^{\circ}$;
- moderately limited according to Maigne $50^{\circ}$ to $70^{\circ}$ according to Wallace ${ }^{31}$ between $16^{\circ}$ to $69^{\circ}$

- severely limited according to Maigne $<50^{\circ}$ according to Wallace $<15^{\circ}$;

- kappa side whose rotation is most limited $=0.57^{19}$.

\section{3-5 - 2 - Flexing and extension movement $^{31}$}

\section{- Flexing}

- normal > $45^{\circ}$ (according to Rozenberg $>60^{\circ}$ );

- moderately limited $10^{\circ}$ to $44^{\circ}$;

- severely limited $<9^{\circ}$.

\section{- Extension}

- normal > 55 $5^{\circ}$ (according to Rozenberg $>60^{\circ}$ );

- moderately limited $13^{\circ}$ to $54^{\circ}$;

- severely limited $<12^{\circ}$.

\section{- Lateral flexing}

- normal $>40^{\circ}$ (according to Rozenberg $>45^{\circ}$ );

- moderately limited $10^{\circ}$ to $39^{\circ}$

- severely limited $<9^{\circ}$.

- Kappa pain in flexing $=0.71^{19}$

- Kappa pain in extension $=0.76^{19}$

The presence of pain in cervical extension has, nevertheless, been identified as a predictive factor in a prognosis of therapeutic manipulation of the cervical area ${ }^{19}$.

If a passive stretching movement increases cervical mobility, this indicates that the problem is muscular, but if passive stretching is impossible, the problem is articular in origin.

- An occasional clicking sound may be related to muscular hyperactivity 

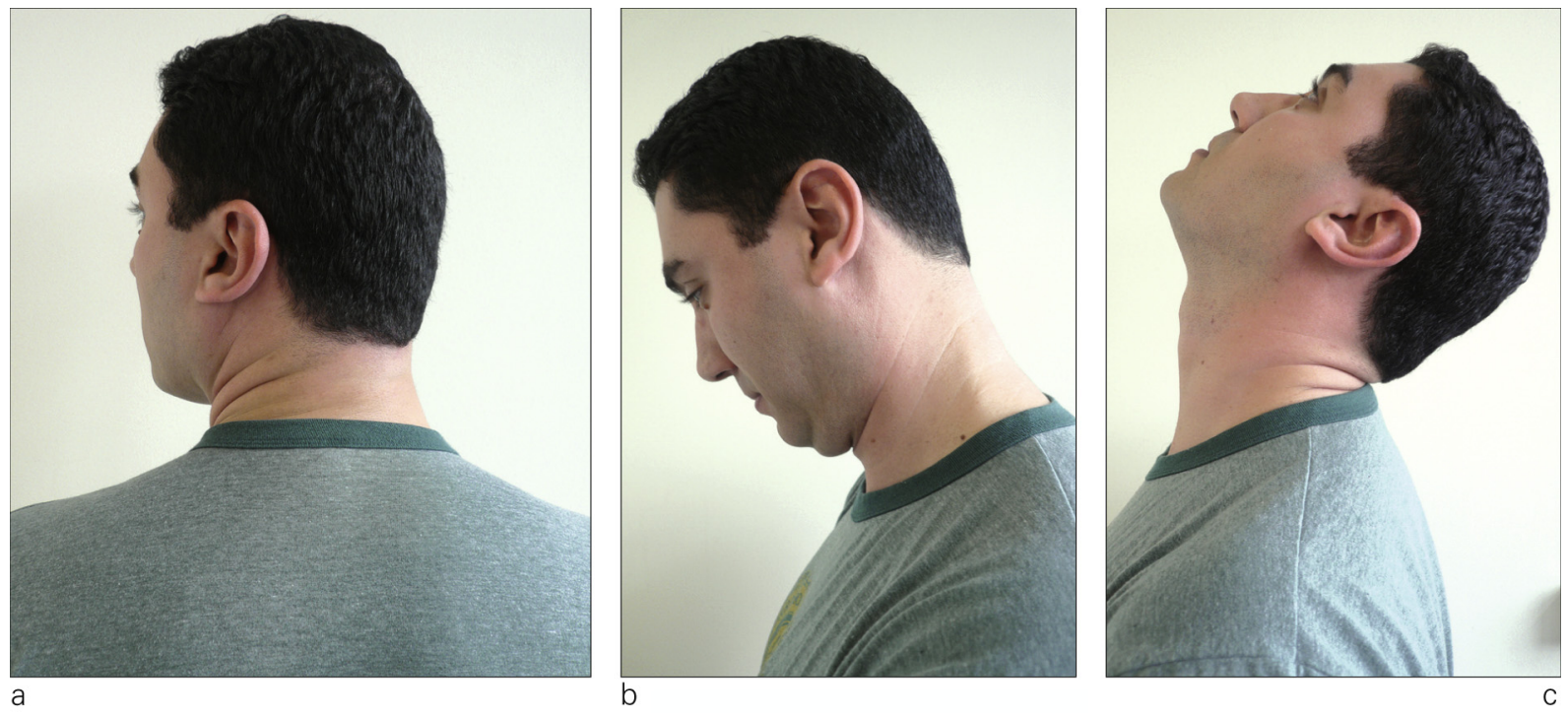

Figures 5 a to $c$

Rotation (a), flexing (b), and extension (c) of the head on the trunk.

that accompanies sporting efforts or carrying a heavy load.

- Regular clicking suggests some type of inter-vertebral malfunction.

- A regular crackling sound suggests a degenerative change.

When there is decreased mobility but no articular sounds this may mean that one vertebra is having trouble sliding over another ${ }^{32}$.

\section{3-5 - 3 - Combination of maximum rotation and flexing/extension movement $^{29}$}

Visscher $^{29}$ has made these statements about cervical movements:

- during active and passive movements kappa value is between 56 and 89;

- during dynamic and static tests against resistance the kappa value is between .43 and .60;
- sensitivity $=70.7$;

- specificity $=69.7$.

\section{3 - 6 - Cranio-cervical posture}

The examiner begins an evaluation of neck morphology on a standing patient (long and thin or short, thick and buried in the shoulders) and of the forward leaning head ${ }^{25}$.

Examiners can make a better and more reproducible evaluation of the antero-posterior inclination of the head by using a plumb line than they can by simple observation ${ }^{26}$.

Overly cephalic cranio-cervical positions are, in most cases, associated with shoulders that rolled forward ${ }^{3-10}$. This could be a risk factor for neck aches $^{25}$ as well as an etiological force in functional problems of the masticatory apparatus.

A mandible, and its condyles ${ }^{23}$, held in a retruded position could be an 

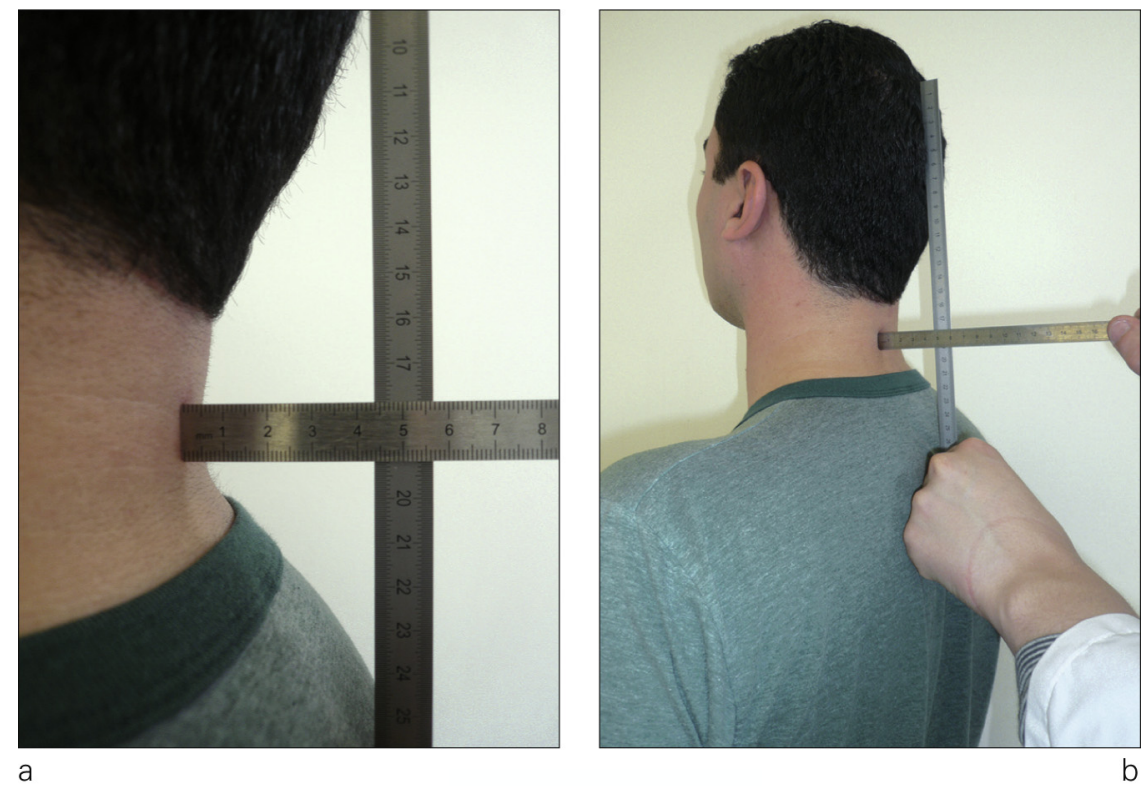

Figures $6 a$ and $b$

Measuring cranio-cervical posture at rest with a special horizontal-vertical ruler.

indicator of this possibility because it would mean the kinematics of the TMJ had been altered as well as the mechanism for muscular control for correcting the anticipated hyper-extension of the head.

The simultaneous activation of the sterno-cleido-mastoid and the muscles of mastication, in particular the masseter and the digastric ${ }^{2}$ could explain why patients with TMD frequently feel pain when their sternocleido-mastoid is palpated ${ }^{1,3,6}$.

Moreover, changes in occlusion can also modify the action of the sterno-

\section{4 - DIAGNOSTIC GROUPINGS}

Functional problems of the masticatory system, whether they are painful or not, cannot easily be placed in one of the classification categories that cleido-mastoid and, as a result, lead to changes in head and neck posture ${ }^{1,32}$.

The hypothesis of an association between head posture and the limitation of mandibular growth could also be postulated ${ }^{23}$.

However, a host of studies have failed to substantiate a supposed correlation between head posture and internal derangements of the temporo-mandibular joint nor have they found any significant differences in this regard between groups of patients with TMD and cranio-cervical disorders as compared to control groups $^{2,12,22,24,26}$.

Samuel Dworkin presented for clinical, and also for research, purposes.

The first diagnostic criteria established for clinical research in the field 


$\begin{array}{ll}\text { la } & \text { muscle pain } \\ \text { lb } & \text { muscle pain with limitation of opening } \\ \text { Ila } & \text { Reducible disc displacement } \\ \text { Ilb } & \begin{array}{l}\text { Non reducible disc displacement } \\ \text { without limitation in opening }\end{array} \\ & \text { IIla } \\ \text { IIIb } & \text { Osthralgia } \\ \text { IIlc } & \text { Osteoarthritis }\end{array}$

Table III

Description of research diagnostic criteria $(R D C)^{24}$.

of Temporo-mandibular disorders were non hierarchical and allowed for a combination of numerous diagnoses to be assigned to an individual patient. They were divided into three groups ${ }^{7}$.

The validity of the algorithms of the Dworkin and LeResche Research Diagnostic Criteria must have sensitivity higher than .75 and a -specificity higher than .95. Only the diagnosis of Group 1, myofacial pain, meets these criteria. It would, then, seem advisable to reformulate the criteria for the algorithms.

Among the principal factors that influence diagnosis are sex of the patient, duration of the symptoms, the characteristics and intensity of

\begin{tabular}{|l|c|c|}
\hline & Initial & After recalculation \\
\hline Group la & 0.83 & 1 \\
Group Ib & 0.76 & 1 \\
Group Ila & 0.26 & 0.64 \\
Group IIb & too low prevalence & ICC not calculated \\
Group IIc & too low prevalence & ICC not calculate \\
Group IIla & 0.16 & 0.73 \\
Group IIIb & too low prevalence & ICC not calculated \\
Group IIIc & too low prevalence & ICC not calculated \\
\hline
\end{tabular}

Table IV

Results obtained before and after calibration by operators. the pain, patient's psychological state, and non-specific physical symptoms ${ }^{27}$.

In 2009, a revision of the RDC/TMD was proposed to improve the diagnostic criteria ${ }^{24}$.

In spite of ongoing questions about it the RDC/TMD remains the benchmark for diagnosis.

So, while we wait for an improved version, we shall use the 1992 formulation for this paper.

Look $^{17}$, in 2009, described the keys to a clinical examination:

- muscular pain: palpation of 16 extraoral and 4 intraoral sites to make a differential diagnosis of la and $\mathrm{lb}$;

- limitation of opening less than $40 \mathrm{~mm}$ in active opening without pain la/lb;

- clicking II;

- articular pain for group III;

- crackling for IIla/IIlb/IIlc.

According to the results, the most reliable finding is the diagnosis of the most common groups: I, a and b, II, a and $\mathrm{b}$, and III, a and $\mathrm{b}$.

Calibrating of the operators with respect to the initial test, clearly improved the results ${ }^{16}$.

\begin{tabular}{|l|c|c|}
\hline \multicolumn{1}{|c|}{ Diagnostic tests } & Specificity & Sensitivity \\
\hline Palpation of the lateral pole & 83.6 & 68.8 \\
Palpation of the posterior pole & 85.2 & 62.2 \\
Mandibular movements & 81.9 & 60.6 \\
Maximum passive opening & 93.4 & 1.6 \\
Clicking & 68.8 & 50.8 \\
Crackling & 85.2 & 29.5 \\
Dynamic tests & 73.7 & 44.2 \\
TMJ manipulation & 80.3 & 39.3 \\
\hline
\end{tabular}

Table $\mathrm{V}$

Specificity and sensitivity for predicting MRI results. 
The results are better for the groups la, lia, and IIla, which can be explained by the results of muscular palpation being tightly related to the pressure generated by the operator and the locale of the site.

According to Manfredini ${ }^{20}$, six tests in the clinical examination provide enough evidence for an examiner to make a positive predictive estimate at the $84.3 \%$ level that an MRI image will show a diagnostically significant articular anomaly. These include:

- palpation of the lateral pole of the TMJ;

- palpaation of the posterior pole of the TMJ;

- sensitivity in the TMJ area during mandibular movements;

- sensitivity in the TMJ area during maximum assisted passive opening;

- articular clicking heard by examiner with a stethoscope;

\section{5 - CONCLUSION}

In the absence of a "gold standard" or distinctive diagnostic procedures that would help examiners differentiate between patients suffering from TMD, the validation of diagnostic entities requires an investigation to determine the homogeneity of group classes, including risk factors, pain history, and response to treatment ${ }^{7}$.

To accomplish this, more in-depth research is required so that an assessment of the triggering factors predisposing patients to onset of TMD and/ or aggravating it can be made as well as delineating a clearer picture of just what TMJ malfunction entails ${ }^{9}$.
- articular crackling heard by examiner with a stethoscope.

In sum, the clinical examination can be a good predictor of what the MRI findings will be.

But the diagnosis of disc displacement is difficult to make primarily because the groups that have no disc displacement are not defined as the groups with no signs or symptoms.

An MRI exam will reveal a disc displacement for 21 to $33 \%$ of asymptomatic patients.

On the other hand, $70 \%$ of patients with painful temporo-mandibular joints have no disc displacement ${ }^{8}$.

Finally, no association between the presence of the absence of pain on muscular palpation and an eccentric position of the condyle has been demonstrated ${ }^{7}$.

Only a small percentage of the population seeks treatment for the symptoms of disc displacement and many asymptomatic patients actually have an articular disc displacement. This is why practitioners are advised not to intervene when patients have no pain because the treatment could potentially be worse than the, possibly non-existent, disease ${ }^{30}$.

With regard to cervical and postural etiology hypotheses, Armijo Olivo ${ }^{2}$ asserts that readers should interpret studies on this topic prudently because of their lack of scientific rigor. Nevertheless, they do indicate that 
there is a connection between the spinal column and neck structures with cranio-facial pain that should not be underestimated.
Future research on this subject may answer the important questions that so far no one has been able to elucidate.

\section{REFERENCES}

1. Andrade AV, Gomes PF, TeixeiraSalmela IF. Cervical spine alignment and hyoid bone positioning with temporomandibular disorders. J Oral Rehabil 2007;34:767-72.

2. Armijo Olivo S, Magee DJ, Parfitt M, Major P, Thie NM. The association between the cervical spine, the stomatognathic system and craniofacial pain: a critical review. J Orofac Pain 2005;20(4):271-87.

3. Augustine C, Makofsky HW, Britt C, Adomsky B, Deshler JM. Use of the Occivator for the Correction of Forward Head Posture, and the Implications for Temporomandibular Disorders: A Pilot Study. J Craniomandibular Pract 2008;26(2):136-43.

4. Bogduk N, McGuirk B. Prise en charge des cervicalgies aiguës et chroniques. Une approche fondée sur les preuves. Paris : Elsevier Masson, 2007.

5. Braun B, Schiffman EL. The validity and predictive value of four assessment instruments for evaluation of the cervical and stomatognathic systems. J Craniomandib Disord 1991;5(4):239-44.

6. Catanzariti JF, Debuse T, Duquesnoy B. Cervicalgies chroniques et dysfonctionnement de I'appareil manducateur. Rev Rhum 2005;72:1283-7.

7. Dworkin SF. Research Diagnostic Criteria for temporomandibular disorders: current status and future relevance. J Oral Rehabil 2010;24(1):48-62.

8. Emshoff R, Rudisch A. Validity of clinical diagnostic criteria for temporomandibular disorders: clinical versus magnetic resonance imaging diagnosis of temporomandibular joint internal derangement and osteoarthrosis. Oral Surg Oral Med Oral Pathol Oral Radiol Endod 2001;91(1):50-5.

9. Emshoff $\mathrm{R}$, et al. Validation of the clinical diagnostic criteria for temporomandibular disorders for the diagnostic subgroupdisc derangement with reduction. J Oral Rehabil 2002;29(12):1139-45.

10. Fransooa P, Fournierb H, Henonc M. Analyse de la posture cervicale. Kinesither Rev 2009;91:58-62.

11. Gomes MB, et al. Palpation and pressure pain threshold: reliability and validity in patients with temporomandibular disorders. J Craniomandibular Pract 2008;26(3):20210.

12. Hackney J, Clawson DB. Relationship Between Forward Head Posture and Diagnosed Internal Derangement of the Temporomandibular Joint. J Orofac Pain 1993;7(4):38690.

13. Hasanain F, Durham J, Moufti A, Steen IN, Wassell RW. Adapting the diagnostic definitions of the RDC/TMD to routine clinical practice: A feasibility study. J Dent 2009;37:955-62.

14. Huddleston Slater JJ, Lobbezoo F, Naeije M. Mandibular movement characteristics of an anterior disc displacement with reduction. J Orofac Pain 2002;16(2):135-42.

15. Jensen R, Rasmussen BK, Olesen J. Cephalic muscle tenderness and pressure pain threshold in headache. A population study. Pain 1993;52:193-9.

16. List T, John MT, Dworkin SF, Svensson P. Recalibration improves interexaminer reliability of TMD examination. Acta Odontol Scand 2006 Jun;64(3):146-52.

17. Look JO, et al. The Research Diagnostic Criteria for temporomandibular disorders. II: reliability of axis I diagnoses and selected clinical measures. J Orofac Pain 2010;24(1):25-34. 
18. Maigne JY. Cervicalgie et manipulation : faire et ne pas faire. Rev Rhum 2008;75(8):770-2.

19. Maigne JY, Chantelot F, Chatellier G. Reproductibilite? interobservateur de I'examen clinique du cou en médecine manuelle. Ann Phys Rehabil Med 2009;52:41-8.

20. Manfredini D, Tognini F, Zampa V, Bosco M. Predictive value of clinical findings for temporomandibular joint effusion. Oral Surg Oral Med Oral Pathol Oral Radiol Endod 2003;96(5):521-6.

21. Manfredini D, Basso D, Salmaso L, GuardaNardini L. Temporomandibular joint click sound and magnetic resonancedepicted disk position: which relationship? J Dent. 2008;36:256-60.

22. Matheus RA, et al. The relationship between temporomandibular dysfunction and head and cervical posture. Appl Oral Sci 2009;17(3):204-8.

23. Ohmure H, Miyawaki S, Nagata J, Ikeda K, Yamasaki K, AlKalaly A. Influence of forward head posture on condylar position. J Oral Rehabil 2008;35:795-800.

24. Ohrbach R, List T, Goulet JP, Svensson P. Recommendations from the International Consensus workshop: Convergence on an orofacial pain taxonomy. J Oral Rehabil 2010 Oct;37(10):807-12.

25. Rozenberg S, Marty M. Cervicalgie : tri diagnostique et examen clinique. Rev Rhum 2008;75:722-7.

26. Silva AG. Reliability and validity of head posture assessment by observation and a fourcategory scale, Man Ther 2010;15(5):490-5.

27. Truelove $\mathrm{E}$, et al. The research diagnostic criteria for temporomandibular disorders. III: Validity of axis I diagnoses. J Orofac Pain 2009;24(1):35-47.

28. Vasconcelos Filho JO, et al. Condylar and disk position and signs and symptoms of temporomandibular disorders in stressfree subjects. J Am Dent Assoc 2007;138(9):1251-5.

29. Visscher CM, Lobbezoo F, de Boer W, van der Zaag J, Verheij JGC, Naeije M. Clinical tests in distinguishing between persons with or without craniomandibular or cervical spinal pain complaints. Eur J Oral Sci 2000;108:475-83.

30. Visscher CM, et al. Diagnostic accuracy of temporomandibular disorder pain tests: a multicenter study. J Orofac Pain 2009;23(2):108-14.

31. Wallace C, Klineberg IJ. Management of Craniomandibular Disorders. Part 1: A Craniocervical Dysfunction Index. J Orofac Pain 1993;7:83-8.

32. Wallace C., Klineberg IJ. Management of Craniomandibular Disorders. Part 2: Clinical Assessment of Patients with Craniocervical Dysfunction. J Orofac Pain 1994;8(1):42-54

33. Ylinen J, Nykänen M, Kautiainen H, Häkkinen A. Evaluation of repeatability of pressure algometry on the neck muscles for clinical use. Man Ther 2007;12:192-7. 